\title{
Modeling demographic and unobserved heterogeneity in air passengers' sensitivity to service attributes in itinerary choice
}

\author{
Valdemar Warburg \\ Technical University of Denmark \\ Center for Traffic and Transport \\ Bygningstorvet 1 \\ 2800 Lyngby, Denmark \\ Tel.: (+45) 45251524 \\ Email:valde@post.com \\ Chandra Bhat* \\ The University of Texas at Austin \\ Dept of Civil, Architectural \& Environmental Engineering \\ 1 University Station C1761 \\ Austin TX 78712-0278 \\ Tel: 512-471-4535, Fax: 512-475-8744 \\ E-mail: bhat@mail.utexas.edu \\ Thomas Adler \\ Resource Systems Group, Inc. \\ 55 Railroad Row \\ White River Junction, VT 05001 \\ Tel: 802-295-4999, Fax: 802-295-1006 \\ Email: tadler@rsginc.com \\ * Corresponding author
}

TRB 2006: For Presentation and Publication

Paper \# 06-0660

Final Submission: March 31, 2006

Word Count: 7,676 +4 tables $=8,676$ total 


\begin{abstract}
Modeling passengers' flight choice behavior is valuable to understanding the increasingly competitive airline market and predicting air travel demands. This paper estimates standard and mixed multinomial logit models of itinerary choice for business travel, based on a stated preference survey conducted in 2001.

The results suggest that observed demographic and trip related differences get incorrectly manifested as unobserved heterogeneity in a random coefficients mixed logit model that ignores demographic and trip-related characteristics of travelers. Among demographics, gender and income level have the most noticeable effects on sensitivity to service attributes in itinerary choice behavior, but frequent flyer membership, employment status, travel frequency, and group travel also emerge as important determinants. However, there is significant residual heterogeneity due to unobserved factors even after accommodating sensitivity variations due to demographic and trip-related factors. Consequently, substitution rates for each service attribute show substantial variations in the willingness-to-pay among observationally identical business passengers.
\end{abstract}




\section{INTRODUCTION}

Predicting the travel itinerary choices of air passengers has become increasingly important in recent years due to the competitive airline market. One approach to modeling itinerary choices is to construct revealed preference (RP) data by using actual passenger loads, interpreting the shares as probabilities, and defining the choice set as all the itinerary combinations that are available to the decision maker. While RP data represent actual itinerary choices, and therefore provide important information about preferences in a real choice environment, it is unlikely that decision makers consider an extensive enumeration of itinerary combinations in their choice decisions. Another limitation of revealed preference data is the inability to obtain precise estimates of the sensitivity to various air service measures. This is because, while passenger carriers have information on the chosen itinerary, the RP bookings data do not include demographic information.

In this paper, we use a web-based Stated Preference survey conducted by Resource Systems Group in spring, 2001 (prior to the events of 9/11) to examine the itinerary choice behavior of business air travelers. The annual survey represents one of the most comprehensive stated preference design experiments conducted in the air travel behavior field. The current paper uses this data source and considers a wide range of air travel service characteristics, trip-related information, demographic attributes of the traveler, and interactions of these variables to model air itinerary choice behavior. The emphasis is on accommodating the different sensitivities across travelers to air service characteristics based on the trip and demographic attributes of the traveler. In addition, the paper accommodates unobserved sensitivity variations across individuals using a mixed multinomial logit model.

\section{OVERVIEW OF EARLIER AIR TRAVELER CHOICE RESEARCH}

\subsection{Background Studies}

There are several dimensions characterizing air travel choice behavior after a traveler has decided to travel to a particular destination from a particular origin. These include the origin and destination airports in multi-airport regions, the airline carrier choice, the desired departure and arrival times, fare, aircraft types, and airport access mode choice. Several studies have examined one or more of these choices. For example, Skinner (1), Harvey (2), Ashford and Benchemam (3), Ozoka and Ashford (4), Innes and Doucet (5), Thompson and Caves (6), Windle and Dresner 
(7), Basar and Bhat (8), Hess and Polak (9), and Pathomsiri and Haghani (10) all model airport choice in multi-airport regions. Other studies have modeled airport choice along with other dimensions of travel. For instance, Ndoh et al. (11) examine passenger route choice and airport choice; Furiuchi and Koppelman (12) study destination choice and airport choice; Pels et al. (13) analyze airline and airport choice; and Pels et al. (14) and Hess and Polak (9) model the three dimensions of airport access mode choice, airline choice, and airport choice. A few studies have also focused on air traveler choices other than airport choice. These include Proussaloglou and Koppelman (15), Chin (16), Yoo and Ashford (17), and Algers and Beser (18), all of whom examine airline choice.

A majority of the studies discussed above have used a simple multinomial logit model of choice to examine air traveler behavior. A few studies, such as Furiuchi and Koppelman (12), Ndoh et al. (11), and Pels et al. (13), have used a nested logit model to model multidimensional or spatial choices in air travel behavior. But it has been only recently that studies have attempted to consider such important behavioral issues as consideration effects in air travel choices [see Basar and Bhat (8)] and variations in sensitivity across individuals due to unobserved factors [see Hess and Polak $(9,19)$ and Pathomsiri and Haghani (10)]. These studies use a mixing structure over the multinomial logit kernel, either in the form of a discrete distribution [leading to a latent class model as in Basar and Bhat (8)] or in the form of a continuous distribution [leading to the mixed multinomial logit model as in Hess and Polak (9) and Pathomsiri and Haghani (10)]. While being important methodological contributions, the above three studies (along with the rest of the studies discussed earlier) have been rather limited in their perspective of the choices that characterize air travel decisions. Specifically, the Basar and Bhat (8), Hess and Polak (19), and Pathomsiri and Haghani (10) studies focus exclusively on airport choice, while the Hess and Polak (9) study confines its attention to the choices of airport, airline, and access mode. An additional issue with earlier studies that accommodate unobserved taste variations is that they do not adequately accommodate observed taste variations. As emphasized in Bhat (20), it is critical to first accommodate systematic variations in as comprehensive a way as possible, so we are able to explain differences in sensitivity based on tangible, observed, attributes that can be used for targeting and marketing of air service improvements by air carriers and airport management. The introduction of unobserved taste variation should not be in lieu of observed 
taste variation, but only to recognize the inevitable presence of unobserved factors affecting sensitivities, even after the most comprehensive control for observed factors.

\subsection{Two Recent Studies of Importance}

Two recent studies, and the ones most pertinent to the current research effort in the context of addressing the limitations discussed above, are Coldren and Koppelman (21) and Adler et al. (22). Both these studies consider the whole suite of choices (origin and destination, airports in multi-airport regions, airline, fare, departure and arrival times, airport type, and number of connections) using itineraries as the alternatives in their discrete models. This shift of focus from evaluating a few isolated air travel choice dimensions to analyzing the multidimensional set of choices implicit in selecting an itinerary is a significant one in the literature. After all, travelers choose from among various itineraries rather than choosing an airport or an airline. In the next two sections, we discuss the Coldren and Koppelman and Adler et al. studies in more detail.

\subsubsection{The Coldren and Koppelman Study}

This study uses air travel itinerary share data to estimate aggregate hybrid ordered generalized extreme value (OGEV) models to capture inter-itinerary competition. The data are based on detailed records of individual-booked itineraries obtained from a compilation of computer reservation systems (CRS). These bookings data are complemented with air carrier schedule information obtained from the Official Airline Guide (23) and average fares by carrier across all itineraries for each airport pair. The authors use the itinerary building engine of a major carrier to generate the set of feasible itineraries by airport pair, and obtain the share of each itinerary for each airport pair by merging the generated set of feasible itineraries with the bookings data from the CRS. These itinerary shares are modeled as a function of several service characteristics, including itinerary level of service indicators (nonstop, direct, single-connect or double-connect), connection quality, carrier attributes, aircraft type, and departure time.

The Coldren and Koppelman study is, to our knowledge, the most comprehensive published effort that models itinerary choice using actual revealed preference bookings data. The data preparation in the research is a demanding exercise and should serve as a reference basis for data compilation in future revealed preference studies of itinerary choice. In addition, the authors

use an ordered-generalized extreme value structure among the itineraries to accommodate the 
higher sensitivity between itineraries which are "proximate" in departure time. Further, Coldren and Koppelman also consider the higher degree of sensitivity across itineraries sharing a common carrier and a common level-of-service indicator. The overall model takes the form of an Ordered Generalized Extreme Value Nested Logit (OGEV-NL) structure. The results show evidence of higher sensitivity among itineraries along the time, carrier, and level-of-service dimensions, as well as proximate covariance in departure time choice.

Overall, the Coldren and Koppelman study is an important contribution to the literature. However, there are three limitations of the study. First, the bookings data do not include individual demographics (gender, income, employment, etc.) and individual travel characteristics (group travel, frequency of travel, trip purpose, etc.) and as a result only aggregate share models can be estimated with these data. Such share models cannot accommodate sensitivity variations to service attributes based on individual demographic and travel characteristics. Second, the fare data for itineraries between an airport pair vary only by carrier, since itinerary-level fare data were not available to the authors. This limited fare variation among itineraries introduces additional error and potential biases in the estimation of willingness-to-pay. Third, the set of possible itineraries for each individual are based on a comprehensive enumeration based on historical bookings. It is unlikely that individuals consider such an extensive set of itineraries between airport pairs when making their choice.

\subsubsection{The Adler et al. Study}

Unlike the Coldren and Koppelman study that focused on the better representation of the competitiveness structure (sensitivity) across itineraries, the Adler et al. study (22) was motivated by a need to better understand the trade-offs in the many service characteristics in an increasingly option-laden airline industry. For example, low-fare airlines are positioning themselves in the market by flying out of more remote airports, flying circuitous routes with several transfers, and providing "no-frills" service. At the same time, the "legacy" airlines are repositioning themselves through route and schedule re-alignments, pay-for-food services, and varying other service attributes such as seat spacing. Clearly, an understanding of the tradeoffs that individuals use in their itinerary choices becomes critical to airline managers in such an environment. 
The Adler et al. study uses a 2003 internet-based revealed preference/stated preference survey that collected detailed information on the most recent paid domestic air trip of about 600 individuals. The web-based survey, which is annually conducted by Resource Systems Group, Inc., also obtained information from respondents on their preferred ticketing, airport, and airline alternatives, and implemented a stated choice experiment customized to the attributes of the respondent's reported trip. Specifically, a heuristic programmed into the survey software generates a “realistic” itinerary alternative for the respondent's reported trip. Ten such itinerary alternatives are constructed based on a fractional factorial experimental design and presented as alternatives to the actual reported itinerary in ten separate stated choice experiments for each individual. The attributes characterizing the itineraries in the stated choice experiments include airline carrier, airport, access/egress time, flight times, connections, fare, the time difference between the desired arrival time at destination and the scheduled arrival time of the itinerary, aircraft type, and on-time performance. The authors use a mixed multinomial logit model to capture the sensitivity variations to the service attributes mentioned earlier.

The Adler et al. study is, like the Coldren and Koppelman study, an important contribution to the aviation demand literature. The stated preference design in the research reduces correlations among service attributes and facilitates an accurate trade-off analysis. But a limitation of the Adler study is that, like the Coldren and Koppelman study, it does not incorporate the full effects of demographics and trip characteristics on the sensitivity to service attributes.

\subsection{The Current Research}

The current research contributes to the itinerary choice models in the literature by examining the influence of service characteristics using data from a spring 2001 internet-based revealed and stated preference survey (24). A mixed logit model is used to allow random taste variations in the sensitivity to service characteristics. However, in addition, we examine taste variations due to a comprehensive set of demographic and trip characteristics of individuals. These characteristics are available in the data collected by Adler et al., but were not explored in detail previously. The taste differences between various demographic and travel groups are highlighted and discussed. To focus our analysis, we examine itinerary choice models only for business travelers in the current paper. 
The rest of this paper is structured as follows: First, a brief introduction and description of the data is presented in Section 3, followed by a brief overview of the mixed multinomial logit model in Section 4. Section 5 discusses the empirical results, while Section 6 estimates the tradeoffs implied by the empirical results. The final section concludes the paper by summarizing the findings.

\section{THE DATA}

\subsection{Data Source}

The sample used in this paper is drawn from a 2001 online survey of 621 air travelers (24). Respondents were selected from an online consumer panel and screened to include only those individuals who had made a recent paid domestic U.S. air trip. They were compensated for participating in the 30-45 minute web survey and the resulting response rate was just over $60 \%$. The air trips covered a reasonably representative sample of markets and airports in the United States. A total of 28 airline carriers were represented in the sample, including a mix of low cost and network carriers.

In the current analysis, the focus is on business travelers from the set of all respondents. For each traveler, details of the most recent business trip within the U.S. were first collected in the online survey, including the complete itinerary of that trip. In addition, respondents were asked to (a) rank airlines in order of preference (for those with which they were familiar and assuming equal prices), (b) rank their departure airport preference at the home end from a list of airports deemed “reasonable” based on an airport database and respondents' own perceptions, and (c) provide their preferred arrival times at the business or non-home end. After obtaining the above information, an internally coded heuristic in the survey software generates ten sets of alternative itineraries for the outbound (home end to business end) one-way trip based on an experimental design, and presents each alternative itinerary along with the revealed choice itinerary in a series of 10 binary choice exercises to the respondent. The respondent has the choice of choosing her/his revealed choice itinerary or the alternative itinerary in each exercise. The precise definition of, and possible levels for, each attribute in the stated preference experiment is presented in Table 1 . The reader will note that all the attributes in Table 1 correspond to the one-way outbound trip from the home end to the business end. 


\subsection{Sample Description}

In this section, we describe the most important data characteristics relevant to the current paper. For a detailed description of all survey results, the reader is referred to Resource Systems Group (24).

\subsubsection{Market Shares}

There is no universal choice set, but rather generated choice sets for each respondent based on his or her RP alternative. In 70\% of the stated choice questions, the respondents chose their RP alternative. This indicates the presence of inertia, which will be discussed in Section 5.2.10. However, when the airline in the non-RP alternative is the same as in the RP alternative, respondents remained with their RP alternative only $62 \%$ of the time. This suggests that airline loyalty plays a role in itinerary choice.

\subsubsection{Airline Carriers and Preferences}

The most frequently chosen airlines are Delta (18\%), Southwest (15\%), United (12\%), and Northwest (10\%). While the relatively small sample size means that these are not completely reflective of the actual pre-9/11 business market shares, the sample includes a sufficient representation to support modeling of itinerary choices across the major carriers. The respondents' ranking of airlines based on their perception of the quality and service is consistent with their choice of airline in the itinerary. In particular, Delta received the highest ranking by $20 \%$ of the respondents, followed by Southwest and United (both 11\%) and American (10\%).

\subsubsection{Air Fares by Carrier}

The fares by carrier were normalized by the duration of the flight to control for the different lengths of the markets served by different carriers. Delta has the highest reported average fare of \$3.44 per minute, followed by Northwest (\$3.31 per minute) and American (\$3.19 per minute). Continental has the lowest reported average fare (\$2.02 per minute) among the six most chosen

airlines, followed by Southwest (\$2.27 per minute). These results, when taken together with the results in Section 3.2.2, indicate that fares are not the sole criterion in the choice or ranking of air carriers. 


\subsubsection{Preferred Arrival Time Distribution}

Most business passengers in the sample (35\%) prefer arriving at their destination airport in the time interval between 8 a.m. to noon, followed by the time intervals of noon to 4 p.m. (26\%) and 4 p.m. to 8 p.m. (19\%). 16\% prefer arriving before 8 a.m. and only 3\% prefer arriving after 8 p.m. These results are reasonable, considering that most business meetings take place in the morning or afternoon.

\section{THE MIXED LOGIT MODEL}

The mixed logit model generalizes the well-known multinomial logit (MNL) model by allowing a mixing distribution over the multinomial logit kernel. For repeated choice data from the same respondent, as in the current stated choice experiment, the mixed logit structure takes the form shown below:

$$
\begin{aligned}
& P_{q}(\theta)=\int_{-\infty}^{\infty} L_{q}(\beta) f(\beta \mid \theta) d(\beta), \text { where } \\
& L_{q}(\beta)=\prod_{i} \prod_{t}\left(\frac{e^{\beta^{\prime} x_{q i t}}}{\sum_{j} e^{\beta^{\prime} x_{q i}}}\right)^{\delta_{q i t}} .
\end{aligned}
$$

$P_{q}$ is the unconditional probability of the sequence of observed choices of the individual over the alternatives $i(i=1$ or 2 in the current empirical context) and choice occasions $t(t=1,2, \ldots, 10$ in the current empirical context), $x_{q i t}$ is a vector of variables specific to individual $q$, alternative $i$, and choice occasion $t, \beta$ represents parameters which are random realizations from a density function $f\left(\right.$.), $\delta_{q i t}$ is 1 if alternative $i$ is chosen by individual $q$ on choice occasion $t$ and 0 otherwise, and $\theta$ is a vector of underlying moment parameters characterizing $f($.). In our estimations, we consider a normal mixing distribution for $f($.) because of its good convergence properties [the reader is referred to Bhat for recent comprehensive reviews of the mixed logit model $(20,25,26)]$.

The mixed logit model requires the evaluation of analytically intractable multidimensional integrals in the classical estimation approach. The approximation of these integrals is undertaken using simulation techniques using Halton draws [see Bhat (25)]. All estimations are undertaken using the GAUSS matrix programming language. 


\section{EMPIRICAL ANALYSIS}

\subsection{Model specification}

The attributes listed in Table 1 are considered as explanatory variables that potentially affect itinerary choices. In addition, we considered an "inertia" variable to incorporate an overall reluctance to shift from the revealed choice itinerary. The model specifications we considered began with a simple multinomial logit specification with the attributes listed in Table 1 and the inertia variable. Next, we considered interactions of several demographic/trip characteristics with the service attributes. The demographic/trip characteristics included gender, income (for the proportion of business travelers who were not reimbursed by their company), employment sector, number of vehicles owned by household, duration of trip (number of nights at destination), whether or not the traveler checked bags, frequency of air travel (number of U.S. domestic flights in the last year), and day of travel. In addition, we considered the effects of the preferred airline, preferred arrival time, and preferred departure airport (as provided by the respondent before the stated preference experiment) on itinerary choice.

After estimating the multinomial logit models without and with demographic/trip interactions, we proceeded to estimate mixed multinomial logit models without and with demographic/trip interactions. We considered random coefficients on all service attributes (including the inertia variable), except the fare coefficient, which we held fixed for several reasons. First, the use of a normal random coefficient on fare implies that some individuals will have a positive response to fare. Second, fixing the coefficient provides stability to the convergence in the maximum likelihood estimation (27). Third, using a fixed coefficient makes the computation of willingness-to-pay values convenient, since these values take a simple normal distribution.

The final variable specifications in the models were based on a systematic procedure of eliminating statistically insignificant variables, combined with intuitive considerations and informed by the results of earlier studies. In the specifications, we tested alternative functional forms for continuous demographic/trip variables, including dummy variable effects, logarithmic functional forms, and piecewise linear effects. The final specification was selected based on statistical fit and intuitive considerations. 


\subsection{Multinomial Logit Results}

Table 2 presents the results of the multinomial logit models for business travelers. The first model includes service characteristics, but no demographic/trip interactions, and the second includes service characteristics and their interactions with demographic/trip variables. In the rest of this section, we discuss the impact of each service characteristic in turn in separate sections.

\subsubsection{Air Fare}

The fare coefficient has the expected negative, and statistically significant, value in the model with service characteristics only. The interaction model indicates statistically significant variations in the fare sensitivities based on demographic/trip interactions. In particular, women and individuals traveling in a group are less sensitive to fares than men and individuals traveling alone, respectively (however, note that the fare coefficient continues to remain negative for women and individuals traveling in a group). Further, for business passengers who self-pay (as opposed to their company paying) for their trip, lower household income results in a higher sensitivity to fares. This is the expected income effect on consumption of goods and services. Not surprisingly, household income had no statistically significant interaction effect for business passengers whose travel is paid by their company.

\subsubsection{Flight Time}

Flight time also has the expected negative effect on the utility of an itinerary. The interaction model indicates higher sensitivity to flight time for business travelers employed in transportation or retail trade, and in professional services, relative to those employed in communications, construction, education, finance/insurance, government, health/medical, manufacturing, marketing/market research, and wholesale trade. This is a rather interesting result, which may be a reflection of the differential value companies place on employee time based on the overall market value of the services offered. ${ }^{1}$ Further, the interaction model suggests that passengers, who check in bags, and frequent business travelers, are less time-sensitive than passengers who do not check in bags and who are infrequent business travelers, respectively. Passengers who check in bags may either be intrinsically more time-patient because of personality characteristics

\footnotetext{
${ }^{1}$ This result, however, requires further exploration to understand these variations in flight-time sensitivity. We leave this for future research.
} 
or may be traveling for less time-sensitive activities (after all, these passengers are prepared to spend additional time at the origin and destination airports to check in and retrieve their baggage). Frequent business travelers may have become accustomed to working productively on flights, rendering flight time less onerous.

\subsubsection{On-Time Performance}

The model without interactions shows the expected positive impact of on-time performance on itinerary utility. The model with interactions indicates that this positive impact is retained for all travelers, though the effect varies across passengers. In particular, passengers who check in bags and/or travel frequently are less sensitive to on-time performance, perhaps for the same reasons that they are time-patient. For example, frequent travelers may be able to work productively not only on flights, but also at airports. Another finding is the higher sensitivity of passengers traveling on a Friday or a Saturday to on-time performance.

\subsubsection{Access Time to Airport}

A higher access time to the airport in the itinerary leads to a lower likelihood of choosing that itinerary. This is a well-established result in the several studies that have focused on airport choice [see, for example, Basar and Bhat (8) and Pathomsiri and Haghani (10), who find access time as the dominant determinant of airport choice). The interaction model reflects a lower

sensitivity to access time for individuals with several vehicles in their household, presumably because these passengers are more likely to drive their cars to the airport and view the private time in their vehicle in a less onerous way. On the other hand, passengers traveling on a Friday or a Saturday view access time more onerously than those traveling on other days, consistent with the "edginess" of Friday/Saturday travelers reflected in their higher sensitivity to on-time performance.

\subsubsection{Connecting Flight}

Business travelers stay away from connecting flights, even after controlling for flight times (which includes connection times). However, we did not find a statistically significant difference between having one connection versus two or more connections. The interaction model shows that passengers with checked-in luggage are more tolerant to connections, perhaps because they 
would have less cabin luggage to transport between gates during connections. The "edginess" of Friday-Saturday business travelers is again apparent in their higher intolerance to itineraries with connections.

\subsubsection{Schedule Difference}

The schedule difference for an itinerary, as indicated in Table 1, refers to the difference in arrival time of an itinerary at the destination airport relative to the preferred arrival time (as indicated by the respondent before the stated choice experiments). ${ }^{2}$ In our analysis, we used separate schedule difference variables for arrival before the preferred time (early arrival) and arrival after the preferred time (late arrival) to evaluate any asymmetric effects. Several observations can be made from the results for the schedule difference variables in Table 2. First, travelers, as expected, prefer itineraries that get them to their destination airport close to their preferred time of arrival. Second, there are no statistically significant differences in the schedule difference effect between earlier-than-preferred and later-than-preferred arrivals. Third, the interaction model indicates a lower sensitivity to schedule difference (applicable to both early and late arrivals relative to preferred arrival times) for trips of longer duration. This is rather intuitive, since individuals are likely to have more schedule constraints at their destination if they have short stays, while they can be more flexible if they have longer stays.

\subsubsection{Aircraft Type}

A non-stop itinerary can be associated with four different aircraft types, as presented in the stated choice experiments. These are 1) propeller, 2) regional jet, 3) standard jet (single aisle), and 4) widebody (double aisle). For connecting flights, realistic combinations of these were presented, based on airport pair, airline, and location of connection points. In our analysis, we tested the effect of aircraft type in several ways, including assigning the aircraft type of the primary (longest) flight leg to the entire itinerary, assigning the largest aircraft type in the itinerary to the entire itinerary, assigning the smallest aircraft type to the entire itinerary, and creating separate variables for every possible combination of aircraft type. After extensive testing, the best specification was found to be the one that assigned the smallest aircraft type in the itinerary to

\footnotetext{
2 The 2001 survey did not include a question about preferred departure time, and thus we are unable to capture departure time preferences on itinerary choice.
} 
the entire itinerary. This is also consistent with the Coldren and Koppelman (21) formulation. It is reasonable from a behavioral standpoint that passengers are likely to focus in on the "weakest" link of the entire itinerary from a safety/turbulence experience standpoint. Overall, our results indicate that business travelers prefer itineraries with standard jets relative to propeller or regional jets, and interestingly, also to widebody jets. The interaction model shows that the preference for standard jets is particularly pronounced for frequent travelers. This is reasonable, since frequent travelers are likely to be more familiar with different types of aircraft and will therefore pay more attention to this attribute when selecting an itinerary.

\subsubsection{Airline and Airport Preferences}

As indicated earlier, respondents were asked to rank their preferences of airline and airports prior to undertaking the stated choice exercises. The results in Table 2 are as expected. Individuals most prefer itineraries associated with the airline of their first preference, followed by itineraries associated with the airline of their second and third preferences (relative to itineraries with airlines of lower preference). Similarly, respondents prefer itineraries associated with airports of their first preference (passengers were asked to rank airports without regard to access times, so that the rankings could be a reflection of their subjective assessment of the services and quality offered by airports; however, our estimations showed that removing access time from the specification increased the magnitude and significance of the first-ranked airport, indicating that access time was considered by respondents in ranking airports). The estimation results did not indicate preferences for itineraries associated with airports ranked second, third, or fourth compared to lower-ranked airports.

\subsubsection{Frequent Flyer Membership}

Previous studies have indicated the strong effect of frequent flyer membership on airline choice $(15,16,22,28)$. This finding of previous studies is reinforced in the current study. Specifically, passengers prefer itineraries with airlines with whom they are frequent flyers. The loyalty effect is higher for the elite members compared to standard or medium level members. The loyalty effects are only marginally significant, because of the correlation between the preferred airline and frequent flyer membership. 


\subsubsection{Inertia Effect}

The stated choice experiments were designed such that the alternative itineraries generated by the computer were not dominated by the revealed choice alternative. However, in $70 \%$ of the stated choice experiments, respondents chose their current (revealed choice) alternative instead of the computer-generated itinerary. This is likely due to an inertia effect, where individuals are accustomed to their itinerary and stay with it. The results of the model without interactions support the inertia effect. However, the interaction model indicates that the inertia effect is only prevalent for individuals who purchase their tickets directly from the airline (such individuals are likely to be loyal to their preferred airline). For individuals who purchase their ticket from an agent or online, the inertia effect is neutralized (such individuals are likely to be those who shop around and explore different options, and thus may be more willing to accept the alternative itinerary in the SP experiments). Finally, individuals who purchase their tickets elsewhere (predominantly corporate travel offices) tend to be less likely to stick to their RP alternative. That is, these individuals prefer the alternative computer generated itinerary, everything else being equal. This is likely due to situations in which the respondent does not make the booking personally. Travelers whose corporate travel offices purchase their ticket may not be involved in the process themselves, and may therefore be more disposed to question whether the travel office made the right choice when selecting an itinerary and/or may have airline preferences different from the preferred corporate airline.

\subsubsection{Model Fit Comparison Between the Two MNL Models}

Table 2 indicates the statistical significance of several of the interaction terms in the model with demographic/trip related interactions. One can formally test the two models in Table 2 using a nested likelihood ratio test. The test value is $-2(-453.49+392.00)=122.98$, which is

substantially larger than the table chi-squared value with 18 degrees of freedom at any reasonable level of significance. Thus, one can strongly reject the null hypothesis that demographic/trip-related variables do not play a role in moderating the sensitivity to service characteristics in air itinerary choice. 


\subsection{The Mixed Multinomial Logit Results}

The mixed multinomial logit model is used to accommodate taste variations due to unobserved individual factors. Specifically, we impose normal distributions for the sensitivity to the service characteristics. Note that we do not impose random coefficients on the airline and airport preference variables, and the frequent flyer membership variable, since they are already associated with the individual and are not service attributes of the itinerary. In addition, we do not introduce unobserved taste variations to the fare variable for the reasons discussed in Section 5.1.

Table 3 shows the results of the mixed multinomial logit estimation with no interaction variables and including interactions variables. In the first model, the standard deviations of early arrival relative to preferred arrival time, aircraft type, and the inertia variable are not significant, while the rest of the service characteristics have significant standard deviations. Overall, the results show that there is unobserved heterogeneity in respondent's itinerary choice.

In the MMNL model with demographic/trip-related interactions, the standard deviations characterizing random taste variations in flight time and the scheduled time difference variables also turned out to be statistically insignificant. Thus, the interaction model indicates random taste variation only in response to on-time performance, access time to the airport, and presence of a connecting flight. Further, it can be observed that the distribution due to random effects, in general, becomes narrower in the interaction model compared to the model with only service characteristics. While the coefficients of the two models cannot be directly compared due to differing overall scales, one can characterize the variation of each random coefficient relative to the mean value. For example, in the model with service characteristics only, the ratio of the standard deviation to the mean coefficient for on-time performance is $3.381 / 1.611=2.10$. In the model with interactions, the equivalent ratio for individuals with the highest level of variation relative to the mean (corresponding to frequent travelers who check-in their bags), is $2.553 /(3.970-0.141-2.526)=1.96$. The equivalent ratio for the vast majority of frequent travelers who do not check-in their baggage is $2.553 /(3.970-0.141)=0.67$. Overall, the level of random taste variation reduces substantially after accounting for systematic taste variations. This indicates the pitfalls of ignoring systematic taste variation when accommodating random taste variation. 


\subsubsection{Model Fit Comparisons Between the Two MMNL Models}

The model without demographic/trip-related interactions and the model with demographic/triprelated interactions can be compared using a likelihood ratio test. To be fair, we dropped the insignificant standard deviation estimates on the "early arrival relative to preferred arrival time", aircraft type, and the inertia variables from the "service characteristics only" model for the statistical test. The likelihood ratio test value is 64 , which is higher than the chi-squared table value with 13 degrees of freedom at even the 0.001 level of significance. Thus, even in the MMNL framework, one can strongly reject the null hypothesis of no demographic/trip-related interaction effects.

\subsubsection{Model Fit Comparisons Between the MMNL and MNL Models}

The MMNL models in Table 2 can be compared to their respective MNL counterparts in Table 1 using standard likelihood ratio tests. For both the "service characteristics only" model and the model with "demographic/trip-related interactions", the MMNL model clearly turns out to have a statistically significant superior fit. This suggests the importance of accommodating random taste variations. However, it is also illustrative to compare the performance of the MNL model with "demographic/trip-related interactions" to the MMNL model with "service characteristics only". The two models have about the same $\bar{\rho}_{c}^{2}$ value (see Tables 2 and 3). This highlights the importance of accommodating systematic variation in as comprehensive a way as possible before proceeding to introduce random taste variations.

\subsubsection{Trade-Off Analysis}

In this section, we discuss the results of trade-off calculations for the six service characteristics of flight time, on-time performance, access time to airport, connecting flights, schedule time difference, and aircraft type. The focus is only on the MMNL models. In the MMNL model with "service characteristics only", we do not consider the insignificant standard deviations for "early arrival time relative to preferred arrival time", "aircraft type", and "inertia” variables. The results in Table 4 show that travelers are, on average, willing to pay $\$ 36$ for a one-hour reduction in flight time, $\$ 9$ for an improvement in on-time performance by 10\%, $\$ 91$ for a one hour reduction in airport access time, $\$ 76$ for a non-stop itinerary compared to a connecting itinerary, $\$ 10$ for 
reducing the schedule time difference for early arrivals by an hour, $\$ 22$ for reducing the schedule time difference for late arrivals by an hour, and $\$ 21$ for traveling on a standard jet compared to other aircraft types. These trade-off values provide information on the relative values of service attributes that could be used by airline carriers and airport management in evaluating service changes. It is also important to note that there is considerable random variation around these mean trade-off values in the MMNL model with service characteristics. These variations could be used to identify clusters of individuals with different preferences who could, in theory, be targeted by specific service changes.

The mean trade-off values vary by demographic/trip-related characteristics of the traveler in the MMNL model with demographic/trip-related interactions. It is straightforward to compute the mean values for any group of travelers. For example, the mean willingness to pay (WTP) for a one-hour reduction in flight times for individuals with the following characteristics - male, traveling alone, company-paid ticket, not employed in transportation, retail or professional services, 2 air trips per year, no bags checked-in, and traveling Sunday through Thursday - is $[(-1.271+2 * 0.041) /-1.744] \times 60=\$ 40.90$. The customized WTP values for each market segment of travelers provides information to air carriers and airport management that could be used to more effectively position and target their service improvements. To arrive at a consolidated mean WTP and standard deviation for service characteristics in the interactions model, we weight the WTP for each segment by the proportion of travelers in that segment in the sample and compute a weighted average. The results are provided in the final column of Table 4. A comparison of the mean WTP values between the "service characteristics only" model and the interactions model indicates an underestimation in the WTPs for flight time, on-time performance, early arrival relative to preferred arrival time, and aircraft type in the former model, and an overestimation of the WTPs for access time, non-stop flights, and late arrival relative to preferred arrival time. Further, the overall levels of variation due to unobserved factors in the WTPs have been reduced in the interaction model for all service attributes except the "connecting flight" variable.

\section{CONCLUSIONS}

This paper contributes to the air travel behavior analysis area by estimating an itinerary choice model that considers taste variations in air service characteristics due to both observed 
traveler/trip characteristics and unobserved factors. The research is part of an important shift in the field from examining isolated air travel choice dimensions to analyzing the multidimensional set of choices implicit in selecting an itinerary.

Two general observations may be drawn from the empirical results. First, and most importantly, the results highlight the importance of considering demographic/trip interactions with service characteristics in a comprehensive manner. There are important and statistically significant sensitivity variations to service characteristics across traveler and trip segments, which are masked when the interactions are ignored. Consequently, ignoring the interactions leads to (a) an inability to understand the differential trade-offs between, and willingness to pay (WTP) for, service characteristics across different sub-populations of the air travel market, (b) inconsistent estimates of the trade-offs and WTP values for the air travel market as a whole, (c) inappropriately high manifestations of random taste variation, and (d) significantly poorer fit measures. In fact, with respect to model fit, the results indicated that a simple multinomial logit model with comprehensive consideration of demographic/trip interactions provides as good a fit as a mixed multinomial logit model with no consideration of demographic/trip interactions. In addition to these empirical considerations, from a fundamental theoretical and model-building standpoint, it is critical to first accommodate systematic variations comprehensively before proceeding to consider random taste variation. As indicated by Bhat (20), the introduction of unobserved taste variation should not be in lieu of observed taste variation, but only to recognize the inevitable presence of unobserved random variations even after the most comprehensive control of observed factors. Second, there are statistically significant random taste variations (across individuals and trips) to air service characteristics, even after incorporating demographic/trip interactions. Ignoring these random taste variations leads to inconsistent tradeoff and WTP values, and significantly poorer model fit statistics. Overall, the results highlight the importance of considering both systematic and random taste variations to (1) effectively position and target air service improvements and (2) accurately predict air travel demand.

There are also several specific and important results from the analysis regarding the service determinants of itinerary choice. First, women, individuals traveling in a group, and high income earners are less sensitive to fares then men, individuals traveling alone, and low income earners, respectively (the result regarding income is applicable only to paying travelers, not company-paid travelers). Second, frequent travelers and travelers who check in bags are more 
time-patient, less likely to be influenced by on-time performance, and more tolerant to connections than occasional travelers and travelers who do not check bags. Third, travelers on Fridays and Saturdays highly value on-time performance, access time, and non-stop flights relative to business travelers on other days of the week. Fourth, travelers staying at their destinations for short periods of time are more sensitive (than travelers staying for long periods) to arriving at their destination airport close to their desired arrival time. Fifth, travelers highly value reductions in access times to airports and non-stop flights; specifically, travelers are willing to pay, on average, about $\$ 68$ for a one-hour saving in access time to the airport and about $\$ 69$ more for a non-stop flight itinerary relative to a connecting flight itinerary.

\section{ACKNOWLEDGEMENTS}

The authors appreciate the comments of five anonymous reviewers on a previous version of the paper. The authors would also like to thank Lisa Macias for her help in typesetting and formatting this document. Finally, the second author would like to dedicate his part of the research efforts to his Father, Dr. Ramalinga Bhat, who passed away in May 2005. 


\section{REFERENCES}

1. Skinner, R. E. Jr. Airport Choice: An Empirical Study. Transportation Engineering Journal, Vol. 102, 1976, pp. 871-883.

2. Harvey, G. Airport Choice in a Multiple Airport Region. Transportation Research A, Vol. 21, No. 6, 1987, pp. 439-449.

3. Ashford, N. and M. Benchemam. Passengers' Choice of Airport: An Application of the Multinomial Logit Model, Transportation Research Record, No. 1147, 1987, pp. 1-5.

4. Ozoka, A. I. and N. Ashford. Application of Disaggregate Modelling in Aviation Systems Planning in Nigeria: A case study. Transportation Research Record, No. 1214, 1989, pp. 10-20.

5. Innes, J. D. and D. H. Doucet. Effects of Access Distance and Level of Service on Airport Choice. Journal of Transportation Engineering, Vol. 116, 1990, pp. 507-516.

6. Thompson, A. and R. Caves. The Projected Market Share for a New Small Airport in the South of England. Regional Studies, Vol. 27, 1993, pp. 137-147.

7. Windle, R. and M. Dresner. Airport Choice in Multi-Airport Regions. Journal of Transportation Engineering, Vol. 121, 1995, pp. 332-337.

8. Basar, G. and C. R. Bhat. A Parameterized Consideration Set Model for Airport Choice: An Application to the San Francisco Bay Area. Transportation Research B, Vol. 38, No. 10, 2004, pp. 889-904.

9. Hess, S. and J. W. Polak. Mixed Logit Modeling of Airport Choice in Multi-Airport Regions. Presented at $84^{\text {th }}$ Annual Meeting of the Transportation Research Board, Washington, D.C., 2005.

10. Pathomsiri, S. and A. Haghani. Taste Variation in Airport Choice Models. Presented at $84^{\text {th }}$ Annual Meeting of the Transportation Research Board, Washington, D.C., 2005.

11. Ndoh, N. N., D. E. Pitfield, and R. R. Caves. Air Transportation Passenger Route Choice: A Nested Multinomial Logit analysis. In Fisher, M. M., P. Nijkamp, and Y. Y. Papageorgiou (Eds.), Spatial Choices and Processes. Elsevier Science Publishers, Amsterdam, 1990.

12. Furuichi, M. and F. S. Koppelman. An Analysis of Air Traveler's Departure Airport and Destination Choice Behaviour. Transportation Research A, Vol. 28, 1994, pp. 187-195.

13. Pels, E., P. Nijkamp, and P. Rietveld. Airport and Airline Choice in a Multi-Airport Region: An Empirical Analysis for the San Francisco Bay Area. Regional Studies, Vol. 35, 2001, pp. 1-9.

14. Pels, E., P. Nijkamp, and P. Rietveld. Access to and Competition Between Airports: A Case Study for the San Francisco Bay Area. Transportation Research A, Vol. 37, 2003, pp. 71-83.

15. Proussaloglou, K. and F. S. Koppelman. The choice of air carrier, flight, and fare class. Journal of Air Transport Management, Vol. 5, 1999, pp. 193-201. 
16. Chin, A. T. H. Impact of Frequent Flyer Programs on the Demand for Air Travel. Journal of Air Transportation, Vol. 7, 2002, pp. 53-86.

17. Yoo, K. E. and N. Ashford. Carrier Choices of Air Passengers in Pacific Rim: Using Comparative Analysis and Complementary Interpretation of Revealed Preference and Stated Preference Data. Transportation Research Record, No. 1562, 1996, pp. 1-7.

18. Algers, S. and M. Beser. Modeling Choice of Flight and Booking Class: A Study Using Stated Preference and Revealed Preference Data. International Journal of Service Technology and Management, Vol. 2, Nos.1-2, 2001.

19. Hess, S. and J. W. Polak. On the Use of Discrete Choice Models for Airport Competition with Applications to the San Francisco Bay area Airports. Paper presented at the $10^{\text {th }}$ triennial World Conference on Transport Research, Istanbul, 2004.

20. Bhat, C.R. Simulation Estimation of Mixed Discrete Choice Models Using Randomized and Scrambled Halton Sequences. Transportation Research B, Vol. 37, No. 9, 2003, pp. 837-855.

21. Coldren, G. M. and F. S. Koppelman. Modeling the Underlying Competitive Dynamic among Air-travel Itineraries with Ordered Generalized Extreme Value Models. Presented at $84^{\text {th }}$ Annual Meeting of the Transportation Research Board, Washington, D.C., 2005.

22. Adler, T., C. S. Falzarano, and G. Spitz. Modeling Trade-offs in Air Itinerary Choices. Presented at $84^{\text {th }}$ Annual Meeting of the Transportation Research Board, Washington, D.C., 2005.

23. OAG Worldwide Limited. Official Airline Guide. Bedfordshire, LU5 4HB, United Kingdom, 2001.

24. Resource Systems Group. Air Travel 2001. What do they tell us about the future of US air travel? Industry report, 2001.

25. Bhat, C.R. Quasi-Random Maximum Simulated Likelihood Estimation of the Mixed Multinomial Logit Model. Transportation Research B, Vol. 35, 2001, pp. 677-693.

26. Bhat, C.R. Incorporating Observed and Unobserved Heterogeneity in Urban Work Mode Choice Modeling. Transportation Science, Vol. 34, No. 2, 2000, pp. 228-238.

27. Train, K. A Comparison of Hierarchical Bayes and Maximum Simulated Likelihood for Mixed Logit. Working Paper, Department of Economics, University of California, Berkeley, 2001.

28. Proussaloglou, K. E. Air Carrier, Fare Class and Flight Demand: An Individual Choice Approach. PhD Dissertation, Northwestern University, Evanston, Illinois, 1992. 


\section{LIST OF TABLES}

TABLE 1 Definition of Attributes Characterizing an Itinerary and Possible Levels of Each Attribute

TABLE 2 Multinomial Logit (MNL) Model Results

TABLE 3 Mixed Multinomial Logit (MMNL) Model Results

TABLE 4 Trade-Off Values Calculated from MMNL Results 
TABLE 1 Definition of Attributes Characterizing an Itinerary and Possible Levels of Each Attribute ${ }^{\ddagger}$

\begin{tabular}{|c|c|c|}
\hline Attribute & Definition & Possible Levels of Attribute \\
\hline Fare & Cost of itinerary (one way) & $\begin{array}{l}\text { Varied based on design around the price paid by } \\
\text { respondent for the RP itinerary }\end{array}$ \\
\hline Flight time & Total departure to arrival gate time & $\begin{array}{l}\text { Varied based on design, while maintaining realistic flight } \\
\text { times }\end{array}$ \\
\hline On-time performance & $\begin{array}{l}\text { Percentage of times the flight itinerary is on time as } \\
\text { defined by the Federal Aviation Administration }\end{array}$ & Varied in $10 \%$ intervals between $50 \%$ and $90 \%$ \\
\hline Access time $^{\S}$ & $\begin{array}{l}\text { Time of travel from respondent supplied trip end } \\
\text { location and airport location at departure (home) end }\end{array}$ & -- \\
\hline Connections & $\begin{array}{l}\text { The number of connections in traveling from the } \\
\text { origin airport to the destination airport }\end{array}$ & Non-stop, one stop, and two stops \\
\hline Schedule time difference & $\begin{array}{l}\text { Time representing difference between itinerary’s } \\
\text { arrival time and desired arrival time at destination } \\
\text { airport }\end{array}$ & Varied based on design \\
\hline Aircraft type & Equipment used in itinerary & $\begin{array}{l}\text { Propeller, regional jet, standard jet (single aisle), widebody } \\
\text { jet (double aisle), and additional } 12 \text { combinations of these } \\
\text { for "connecting flight" itineraries }\end{array}$ \\
\hline Airline & Airline carrier in itinerary & $\begin{array}{l}\text { All US domestic airlines operating scheduled commercial } \\
\text { service in } 2001\end{array}$ \\
\hline Airport & Departure airport & $\begin{array}{l}\text { All airports deemed "reasonable" from airport database } \\
\text { and respondent-identified list of airports }\end{array}$ \\
\hline
\end{tabular}

\footnotetext{
${ }^{\ddagger}$ All attributes correspond to the one-way outbound trip from the home-end (origin) to the business-end (destination).
}

${ }^{\S}$ This access time corresponds to travel to/from the origin (i.e., departure) airport. All alterative itineraries have the same destination airport. 
TABLE 2 Multinomial Logit (MNL) Model Results

\begin{tabular}{|c|c|c|c|c|}
\hline \multirow[t]{2}{*}{ Variables } & \multicolumn{2}{|c|}{$\begin{array}{c}\text { Service } \\
\text { characteristics only }\end{array}$} & \multicolumn{2}{|c|}{$\begin{array}{l}\text { Demographic/trip } \\
\text { related interactions }\end{array}$} \\
\hline & $\beta$ & $t$-stat & $\beta$ & $t$-stat \\
\hline $\begin{array}{l}\text { Fare (100 \$) } \\
\text { Female travelers } \\
\text { Traveling in a group ( } 2 \text { or more) } \\
\text { Fare/income for self-paying travelers (per } \$ 100 \text { yearly salary) }\end{array}$ & -1.118 & -10.43 & $\begin{array}{r}-1.316 \\
0.450 \\
0.340 \\
-5.364\end{array}$ & $\begin{array}{r}-8.59 \\
1.97 \\
1.50 \\
-3.56\end{array}$ \\
\hline $\begin{array}{l}\text { Flight time (in 100s of min.) } \\
\text { Employment: Transportation or retail trade } \\
\text { Employment: Professional services } \\
\text { Employment: Other (base) } \\
\text { Bags checked in } \\
\text { Frequent travelers (\# yearly air trips) } \\
\end{array}$ & -0.687 & -5.39 & $\begin{array}{r}-1.190 \\
-1.469 \\
-0.893 \\
0 \\
0.421 \\
0.043 \\
\end{array}$ & $\begin{array}{r}-4.43 \\
-2.06 \\
-1.95 \\
N / A \\
1.40 \\
2.18\end{array}$ \\
\hline $\begin{array}{l}\text { On-time performance } \\
\text { Bags checked in } \\
\text { Frequent travelers (\# yearly flights) } \\
\text { Travel on a Friday or Saturday } \\
\end{array}$ & 0.866 & 4.13 & $\begin{array}{r}1.967 \\
-1.132 \\
-0.098 \\
1.561 \\
\end{array}$ & $\begin{array}{r}4.29 \\
-2.51 \\
-3.38 \\
2.11\end{array}$ \\
\hline $\begin{array}{l}\text { Access time to airport (in 100s of min.) } \\
\text { Vehicle owners (\# vehicles in household) } \\
\text { Travel on a Friday or Saturday }\end{array}$ & -1.072 & -6.62 & $\begin{array}{r}-3.685 \\
1.265 \\
-1.353\end{array}$ & $\begin{array}{r}-6.29 \\
5.17 \\
-2.84\end{array}$ \\
\hline $\begin{array}{l}\text { Connecting flight } \\
\text { Bags checked in } \\
\text { Travel on a Friday or Saturday }\end{array}$ & -0.711 & -5.41 & $\begin{array}{r}-0.908 \\
0.631 \\
-1.104 \\
\end{array}$ & $\begin{array}{r}-3.99 \\
2.11 \\
-2.28 \\
\end{array}$ \\
\hline $\begin{array}{l}\text { Schedule time difference (in 100s of min.) } \\
\text { Early arrival relative to preferred arrival time } \\
\text { Late arrival relative to preferred arrival time } \\
\text { Duration of stay (\# nights at destination) } \\
\end{array}$ & $\begin{array}{l}-0.204 \\
-0.311\end{array}$ & $\begin{array}{l}-1.03 \\
-2.26\end{array}$ & $\begin{array}{r}-0.588 \\
-0.606 \\
0.048 \\
\end{array}$ & $\begin{array}{r}-2.35 \\
-3.09 \\
1.68 \\
\end{array}$ \\
\hline $\begin{array}{l}\text { Aircraft type: Standard jet } \\
\text { Frequent travelers (\# yearly flights) }\end{array}$ & 0.431 & 3.34 & $\begin{array}{l}0.416 \\
2.363 \\
\end{array}$ & $\begin{array}{l}2.34 \\
1.39 \\
\end{array}$ \\
\hline $\begin{array}{l}\text { Airline and airport preferences } \\
\text { Airline: First preferred } \\
\text { Airline: Second or third preferred } \\
\text { Airport: First preferred }\end{array}$ & $\begin{array}{l}0.492 \\
0.236 \\
0.382\end{array}$ & $\begin{array}{l}2.77 \\
1.49 \\
2.56\end{array}$ & $\begin{array}{l}0.687 \\
0.438 \\
0.405\end{array}$ & $\begin{array}{l}3.41 \\
2.46 \\
2.45\end{array}$ \\
\hline $\begin{array}{l}\text { Frequent flyer membership } \\
\text { Standard or medium level member } \\
\text { Elite level member }\end{array}$ & $\begin{array}{l}0.317 \\
0.926\end{array}$ & $\begin{array}{l}1.67 \\
1.23\end{array}$ & $\begin{array}{l}0.413 \\
1.001\end{array}$ & $\begin{array}{l}1.97 \\
1.33\end{array}$ \\
\hline $\begin{array}{l}\text { Inertia (staying with current RP itinerary) } \\
\text { Purchase directly from airline } \\
\text { Purchase from agent or online } \\
\text { Other means of ticket purchase }{ }^{* *} \text { (base) }\end{array}$ & 0.099 & 0.81 & $\begin{array}{r}-1.234 \\
1.663 \\
1.240 \\
0\end{array}$ & $\begin{array}{r}-3.55 \\
3.94 \\
3.47 \\
N / A\end{array}$ \\
\hline Number of observations & & 1180 & & 1180 \\
\hline Number of parameters - $K$ & & 14 & & 32 \\
\hline Log-likelihood at sample shares $L(c)^{\dagger}$ & & -720.80 & & -720.80 \\
\hline Log-likelihood at convergence - $L(\hat{\beta})$ & & -453.49 & & -392.00 \\
\hline Likelihood ratio index $\left(\bar{\rho}_{c}^{2}\right)^{\ddagger}$ & & 0.353 & & 0.413 \\
\hline
\end{tabular}

*Includes communications, construction, education, finance/insurance, government, health/medical, manufacturing, marketing/market research, and wholesale trade.

***Mostly corporate travel offices.

† The log-likelihood value at sample shares corresponds to the case where each individual is assigned a 0.7 probability of staying with the revealed preference alternative for each of her/his choice occasions. This is based on the $70 \%$ choice of the revealed preference alternative in the stated choice experiments.

$\ddagger \bar{\rho}_{c}^{2}=1-\frac{[L(\hat{\beta})-(K-1)]}{L(c)}$ 
TABLE 3 Mixed Multinomial Logit (MMNL) Model Results

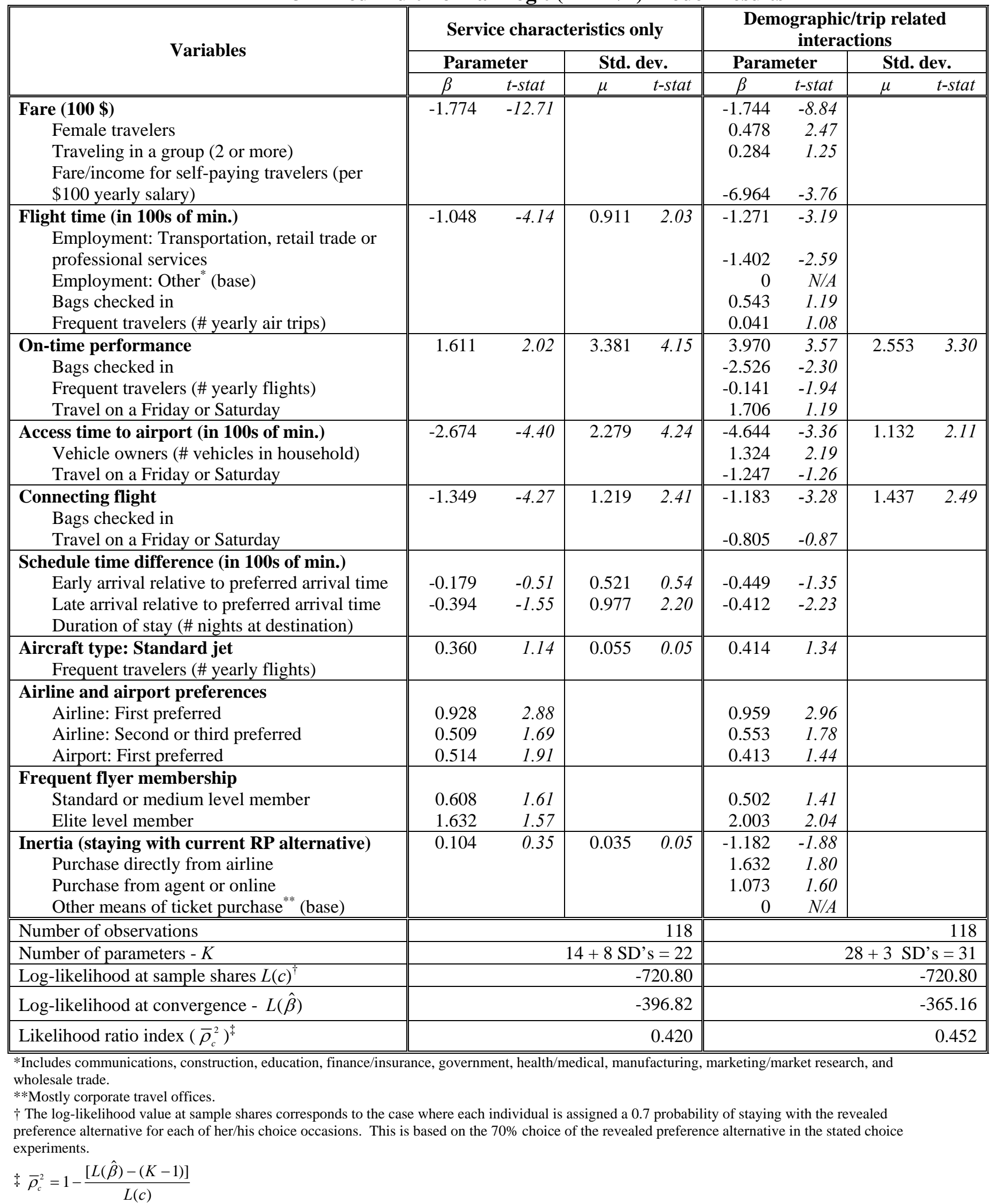


TABLE 4 Trade-Off Values Calculated from MMNL Results

\begin{tabular}{|c|c|c|c|c|}
\hline \multirow[t]{2}{*}{ Service attributes } & \multicolumn{2}{|c|}{$\begin{array}{c}\text { Service characteristics only } \\
\text { model }\end{array}$} & \multicolumn{2}{|c|}{$\begin{array}{l}\text { Model with demographic/trip } \\
\text { related interactions }\end{array}$} \\
\hline & Mean & SD & Mean & $\mathrm{SD}$ \\
\hline Flight time (-1 hour) & $\$ 36$ & 31 & $\$ 42$ & - \\
\hline On-time performance (+10 \%) & $\$ 9$ & 19 & $\$ 10$ & 14 \\
\hline Access time to airport ( -1 hour) & $\$ 91$ & 77 & $\$ 68$ & 36 \\
\hline Connecting flight (WTP for non-stop) & $\$ 76$ & 69 & $\$ 69$ & 76 \\
\hline \multicolumn{5}{|l|}{ Schedule time difference } \\
\hline Early arrival relative to preferred arrival time (-1 hour) & $\$ 10$ & - & $\$ 14$ & - \\
\hline Late arrival relative to preferred arrival time (-1 hour) & $\$ 22$ & 33 & $\$ 13$ & - \\
\hline Aircraft type: Standard jet (vs. other aircraft) & $\$ 21$ & - & $\$ 22$ & - \\
\hline
\end{tabular}

